[Article]

\title{
不同浓度 $\mathrm{Sn}^{4+}$ 离子掺杂 $\mathrm{TiO}_{2}$ 的结构、性质和光催化活性
}

$$
\text { 张 鹏 } 1,2 \text { 赵路松 }{ }^{1,2} \text { 姚江宏 }{ }^{1,2} \text { 曹亚安 }{ }^{1,2, *}
$$

('南开大学物理科学学院, 天津 300071; 2南开大学泰达应用物理学院, 弱光非线性光子学教育部重点实验室, 天津 300457)

\begin{abstract}
摘要：采用溶胶-凝胶法制备出纯 $\mathrm{TiO}_{2}$ 和不同浓度 $\mathrm{Sn}^{4+}$ 离子掺杂的 $\mathrm{TiO}_{2}$ 光催化剂 $\left(\mathrm{TiO}_{2}-\mathrm{Sn} x \%, x \%\right.$ 代表 $\mathrm{Sn}^{4+}$ 离 子掺杂的 $\mathrm{TiO}_{2}$ 样品中 $\mathrm{Sn}^{4+}$ 离子摩尔分数). 利用 $X$ 射线衍射 $(\mathrm{XRD}) 、 X$ 射线光电子能谱(XPS)和表面光电压谱 (SPS)确定了 $\mathrm{TiO}_{2}-\mathrm{Sn} x$ \% 催化剂的晶相结构和能带结构, 结果表明: 当 $\mathrm{Sn}^{4+}$ 离子浓度较低时, $\mathrm{Sn}^{4+}$ 离子进入 $\mathrm{TiO}_{2}$ 晶格, 取代并占据 $\mathrm{Ti}^{4+}$ 离子的位置, 形成取代式掺杂结构 $\left(\mathrm{Ti}_{1-x} \mathrm{Sn}_{x} \mathrm{O}_{2}\right)$, 其掺杂能级在导带下 $0.38 \mathrm{eV}$ 处; 当 $\mathrm{Sn}^{4+}$ 离 子浓度较高时, 掺入的 $\mathrm{Sn}^{4+}$ 离子在 $\mathrm{TiO}_{2}$ 表面生成金红石 $\mathrm{SnO}_{2}$, 形成 $\mathrm{TiO}_{2}$ 和 $\mathrm{SnO}_{2}$ 复合结构 $\left(\mathrm{TiO}_{2} / \mathrm{SnO}_{2}\right), \mathrm{SnO}_{2}$ 的 导带位于 $\mathrm{TiO}_{2}$ 导带下 $0.33 \mathrm{eV}$ 处. 利用瞬态光电压谱和荧光光谱研究了 $\mathrm{TiO}_{2}-\mathrm{Snx} \%$ 催化剂光生载流子的分离和 复合的动力学过程, 结果表明, $\mathrm{Sn}^{4+}$ 离子掺杂能级和表面 $\mathrm{SnO}_{2}$ 能带存在促进光生载流子的分离, 有效地抑制了 光生电子与空穴的复合; 然而, $\mathrm{Sn}^{4+}$ 离子掺杂能级能更有效地增加光生电子的分离寿命, 提高了光生载流子的 分离效率, 从而揭示了 $\mathrm{TiO}_{2}-\mathrm{Sn} x \%$ 催化剂的光催化机理.
\end{abstract}

关键词： $\mathrm{Sn}^{4+}$ 离子掺杂 $\mathrm{TiO}_{2} ; \mathrm{Sn}^{4+}$ 离子浓度; 瞬态光电压; 表面光电压谱; 光生电子的寿命 中图分类号: 0648; 0643

\section{Structure, Characterization and Photocatalytic Properties of $\mathrm{TiO}_{2}$ Doped with Different Content of $\mathrm{Sn}^{4+}$ Ions}

\author{
ZHANG Peng ${ }^{1,2} \quad$ ZHAO Lu-Song ${ }^{1,2} \quad$ YAO Jiang-Hong ${ }^{1,2} \quad$ CAO Ya-An ${ }^{1,2, *}$ \\ ('College of Physics, Nankai University, Tianjin 300071, P. R. China; ${ }^{2}$ Key Laboratory of Weak Light Nonlinear Photonics, \\ Ministry of Education, Teda Applied Physics School, Nankai University, Tianjin 300457, P. R. China)
}

\begin{abstract}
Pure $\mathrm{TiO}_{2}$ and $\mathrm{Sn}^{4+}$ doped $\mathrm{TiO}_{2}\left(\mathrm{TiO}_{2}-\mathrm{Sn} x \%\right)$ photocatalysts were prepared by a sol-gel method, where $x \%$ represents the nominal molar fraction of $\mathrm{Sn}^{4+}$ ions in the $\mathrm{TiO}_{2}$ structure. The crystal structure and energy band structure of the resultant catalysts were characterized by X-ray diffraction (XRD), X-ray photoelectron spectroscopy (XPS), and surface photovoltage spectroscopy (SPS). The results show that for a low content of $\mathrm{Sn}^{4+}$ ions, the $\mathrm{Sn}^{4+}$ ions are doped into the $\mathrm{TiO}_{2}$ lattice and replace lattice $\mathrm{Ti}^{4+}$ ions in a substitute mode $\left(\mathrm{Ti}_{1-x} \mathrm{Sn}_{x} \mathrm{O}_{2}\right)$. The energy levels of these $\mathrm{Sn}^{4+}$ ions are located $0.38 \mathrm{eV}$ below the conduction band. Moreover, the rutile $\mathrm{SnO}_{2}$ crystal structure evolves with increasing content of $\mathrm{Sn}^{4+}$ ions, i.e., a $\mathrm{TiO}_{2} /$ $\mathrm{SnO}_{2}$ structure is formed. The conduction band of $\mathrm{SnO}_{2}$ is located $0.33 \mathrm{eV}$ lower than that of $\mathrm{TiO}_{2}$. The separation and recombination mechanism of the photo-generated carriers was characterized by photoluminescence and transient photovoltage techniques. The results showed that the formation of the energy levels of $\mathrm{Sn}^{4+}$ ions and the conduction band of rutile $\mathrm{SnO}_{2}$ can enhance the separation of the photogenerated carriers, and suppress the recombination of photo-generated carriers. However, the energy levels of $\mathrm{Sn}^{4+}$ can lead to a much longer life time and higher separation efficiency of the photo-generated carriers. For different content of $\mathrm{Sn}^{4+}$ in $\mathrm{Sn}^{4+}$ ion doped $\mathrm{TiO}_{2}\left(\mathrm{TiO}_{2}-\mathrm{Sn} x \%\right)$, the abovementioned aspects improve the photocatalytic activity.
\end{abstract}

Received: December 11, 2012; Revised: March 18, 2013; Published on Web: March 18, 2013.

"Corresponding author. Email: caoyaan@yahoo.com; Tel: +86-22-66229598.

The project was supported by the National Natural Science Foundation of China $(51072082,21173121,11074129)$ and National Key Basic Research Program of China (973) (2012CB934201).

国家自然科学基金(51072082, 21173121，11074129)和国家重点基础研究发展规划项目(973) (2012CB934201)资助

(C) Editorial office of Acta Physico-Chimica Sinica 
Key Words: $\mathrm{Sn}^{4+}$-doped $\mathrm{TiO}_{2}$; Content of $\mathrm{Sn}^{4+}$ ions; Transient photovoltage; Surface photovoltage spectroscopy; Life time of photo-generated electrons

\section{1 引 言}

$\mathrm{TiO}_{2}$ 是一种具有应用前景的光催化剂, 多年来 倍受研究学者的重视. ${ }^{1-3}$ 然而, $\mathrm{TiO}_{2}$ 的禁带宽度为 $3.2 \mathrm{eV}$, 仅能吸收紫外光, 而且光生载流子的复合效 率较高, 这些因素又制约着它的光催化效率的提 高. 4.5 实验证明, 金属或非金属掺杂能够扩展 $\mathrm{TiO}_{2}$ 的 光吸收范围, 有效地抑制光生载流子的复合, 提高 其光催化活性. ${ }^{6-11}$

近年来, $\mathrm{Sn}^{4+}$ 离子掺杂 $\mathrm{TiO}_{2}$ 的研究已有文献报 道. ${ }^{12-18} \mathrm{Zhou}$ 等 ${ }^{12}$ 利用水汽输运水分子的方法制备了 $\mathrm{Sn}^{4+}$ 掺杂的 $\mathrm{TiO}_{2}$, 研究表明 $\mathrm{Sn}^{4+}$ 离子取代晶格中的 $\mathrm{Ti}^{4+}$ 原子, 形成取代式掺杂结构; $\mathrm{Sn}^{4+}$ 离子掺杂能有 效地促进光生载流子的分离, 提高 $\mathrm{TiO}_{2}$ 的光催化活 性. Mahanty 等 ${ }^{13}$ 利用溶胶-凝胶法制备了 $\mathrm{Sn}^{4+}$ 离子掺 杂的 $\mathrm{TiO}_{2}$, 研究了 $\mathrm{Sn}^{4+}$ 离子掺杂对 $\mathrm{TiO}_{2}$ 锐钛矿到金 红石晶相转变的影响. $\mathrm{Gu}$ 等 ${ }^{14}$ 报道了 $\mathrm{SnO}_{2} / \mathrm{TiO}_{2}$ 复合 催化剂增加 $\mathrm{H}_{2}$ 的生成量的成果, 结果表明 $\mathrm{SnO}_{2}$ $\mathrm{TiO}_{2}$ 界面间 $\mathrm{Ti}-\mathrm{O}-\mathrm{Sn}$ 键的数量制约了 $\mathrm{H}_{2}$ 的生成 量. Zheng 等 ${ }^{15}$ 利用浸渍-热转化两步法制备了具有 中空结构的 $\mathrm{Sn}^{4+}$ 掺杂 $\mathrm{TiO}_{2}$ 光催化纤维材料, 研究表 明㷽烧温度对材料的相结构、组成、尺寸、形貌以及 催化性能有影响; $\mathrm{Sn}^{4+}$ 的掺入能够提高 $\mathrm{TiO}_{2}$ 的可见 光催化活性. Duan 等 ${ }^{16}$ 利用水热法制备了不同 $\mathrm{Sn}^{4+}$ 含量掺杂 $\mathrm{TiO}_{2}$ 材料, 并指出 $\mathrm{Sn}^{4+}$ 掺杂的浓度能够对 载流子的复合产生影响. 在我们先前的研究中, 已 经报道了 $\mathrm{Sn}^{4+}$ 离子掺杂 $\mathrm{TiO}_{2}$ 的烧结温度对催化剂的 晶相结构和掺杂方式以及 $\mathrm{Sn}^{4+}$ 离子掺杂对 $\mathrm{TiO}_{2}$ 晶相 的转变的影响. ${ }^{17}$ 另外, 还报道了 $\mathrm{Sn}^{4+}$ 离子掺杂对催 化剂光催化活性的影响. ${ }^{18}$ 直至目前, 虽然 $\mathrm{Sn}^{4+}$ 离子 修饰 $\mathrm{TiO}_{2}$ 催化剂的研究已有相关报道, 但是不同浓 度 $\mathrm{Sn}^{4+}$ 离子修饰对 $\mathrm{TiO}_{2}$ 催化剂的晶相结构、能带结 构和光生载流子分离和复合等动力学过程, 以及光 催化活性的影响报道尚少.

本文采用溶胶-凝胶法制备了不同浓度 $\mathrm{Sn}^{4+}$ 离 子掺杂的 $\mathrm{TiO}_{2}-\mathrm{Sn} x \%\left(x \%\right.$ 代表 $\mathrm{Sn}^{4+}$ 离子掺杂的 $\mathrm{TiO}_{2}$ 样品中 $\mathrm{Sn}^{4+}$ 离子所占的摩尔分数) 催化剂; 研究了 $\mathrm{TiO}_{2}-\mathrm{Sn} x \%$ 催化剂的晶相结构和能带结构; 通过瞬 态表面光电压谱(SPS)和激光荧光光谱, 讨论了低浓 度和高浓度 $\mathrm{Sn}^{4+}$ 离子掺杂 $\mathrm{TiO}_{2}-\mathrm{Sn} x \%$ 催化剂的光生 载流子分离和复合动力学过程, 并分析了掺杂能级
和能带结构对光生载流子动力学行为的作用以及 光催化机理.

\section{2 实验部分}

\section{1 催化剂的制备}

采用溶胶-凝胶法, 以 $\mathrm{Ti}\left(\mathrm{OC}_{4} \mathrm{H}_{9}\right)_{4}$ (纯度 $99.0 \%$ ) 和 $\mathrm{SnCl}_{4}$ (纯度 $99.0 \%$ ) 为反应前体, 在快速搅拌下, 将 $12 \mathrm{~mL} \mathrm{Ti}\left(\mathrm{OC}_{4} \mathrm{H}_{9}\right)_{4}$ 缓慢滴加到 $40 \mathrm{~mL}$ 无水乙醇(纯 度 $99.7 \%$ ) 和 $1 \mathrm{~mL}$ 高纯水的混合液中, 得到均匀的淡 黄色的透明液体, 加入一定量的 $\mathrm{HCl}$ 溶液 $(12 \mathrm{~mol}$ $\left.\mathrm{L}^{-1}\right)$ 控制液体的 $\mathrm{pH}$ 值为 0.5 , 放置 $0.5 \mathrm{~h}$ 后, 加入一定 量无水 $\mathrm{SnCl}_{4}$ (纯 $\mathrm{TiO}_{2}$ 的制备是用高纯水替代无水 $\mathrm{SnCl}_{4}$ ), 然后再缓慢滴入 $1 \mathrm{~mL}$ 高纯水, 使其进一步 水解; 继续搅拌 $0.5 \mathrm{~h}$ 后得到的溶胶在室温下放置自 然蒸发, $24 \mathrm{~h}$ 后变为透明的凝胶; 在 $100^{\circ} \mathrm{C}$ 下烘干 $12 \mathrm{~h}, 450{ }^{\circ} \mathrm{C}$ 烧结 $2.5 \mathrm{~h}$, 即制得一组不同浓度 $\mathrm{Sn}^{4+}$ 离 子掺杂的 $\mathrm{TiO}_{2}$ 和纯 $\mathrm{TiO}_{2}$ 样品, 放入干燥器备用; 掺 入 $\mathrm{Sn}^{4+}$ 离子的摩尔数与 $\mathrm{Ti}^{4+}$ 和 $\mathrm{Sn}^{4+}$ 离子的百分含量记 为 $x \%$ (参见表 1 ).

\section{2 光催化反应}

纯 $\mathrm{TiO}_{2}$ 和 $\mathrm{TiO}_{2}-\mathrm{Sn} x \%$ 催化剂光催化降解对氯苯 酚(分析纯, 天津市光复精细化工研究所)反应的实 验在圆柱形玻璃反应器 $(70 \mathrm{~mL})$ 中进行. 以 $400 \mathrm{~W}$ (Philips HPA400/30S, 荷兰)录灯作为外照光源, 辐射 波长 $\lambda>320 \mathrm{~nm}$, 催化剂用量为 $5 \mathrm{mg}$, 反应器距光源 $10 \mathrm{~cm}$, 对氯苯酚溶液内通 $\mathrm{O}_{2}$ 量为 $6 \mathrm{~mL} \cdot \mathrm{min}^{-1}$, 磁力 摚拌保持体系中溶液浓度和温度 $\left((25 \pm 2){ }^{\circ} \mathrm{C}\right)$ 平衡. 对氯苯酚起始浓度为 $5 \times 10^{-5} \mathrm{~mol} \cdot \mathrm{L}^{-1}$, 体积为 40 $\mathrm{mL}(\mathrm{pH}=5.74)$. 采用 4-氨基氨替吡啉比色法测定对 氯苯酚剩余浓度, 并在相同条件下进行空白光解对 比实验. 实验所用化学试剂均为分析纯, 实验用水 为 $\rho \geq 18.0 \mathrm{M} \Omega \cdot \mathrm{cm}$ 高纯水 (所用仪器为 Milli-Q Academic, MILLIPORE, 法国).

\section{3 物性表征}

$X$ 射线衍射谱 $(X R D$, Rigaku D/max- $2500, C u$ 靶, $K_{\alpha}$ 线, 日本) 测定 $\mathrm{TiO}_{2}$ 和 $\mathrm{TiO}_{2}-\mathrm{Sn} x \%$ 样品的晶体 结构, 粒子的平均粒径根据德拜-谢乐公式计算获 得. X 射线光电子能谱(XPS) 在 ESCA Lab 220i-XL 光谱仪上进行 (Thermo Fisher Scientific, $\mathrm{Al}, K_{a}$ 线, 美 国), 所有的谱图按照 C $1 s(284.8 \mathrm{eV})$ 进行校正. 利用 
自制的表面光电压谱仪测定样品的能带结构, SPS 测试装置主要由光源 (XQ-500WA型500 W Xe灯)、 单色仪(WDG30-2)、样品池、锁相放大器(SR830)、斩 波器(SR540)和数据处理系统(计算机)等构成, 其测 试原理如下: 从光源发出的光经单色仪分光, 然后 通过斩波器照到样品上, 样品产生的光电压信号经 锁相放大器放大、数据采集和信号处理后形成 SPS 谱图. 样品的荧光光谱由激光荧光光谱仪测得, 仪 器装置主要由激发光源(NT342/3/UVE, 190-2500 $\mathrm{nm}$ ) [纳秒激光器 Nd:YAG (NL303G, $325 \mathrm{~nm}$, 脉冲 半宽 $5 \mathrm{~ns}$ )、Harmanics 发生器(SHG, THG) 和光参量 振荡器(OPO) PG122], 单色仪(MS3504)和信号检测 器(PMT, Hamamatsu R928)组成. 另外, 测试系统包 括数据采集(DAQ)、数字转换(PICO ADC- 200/100) 和用于信号聚焦收集的光学系统. 样品的瞬态光电 压谱由自制的瞬态光电压装置测定, 其仪器装置主 要由激光光源(NT342/3/UVE, 190-2500 nm)、样品 池、 $500 \mathrm{MHz}$ 的数字示波器(TDS 5054 Tektronix)和 数据处理系统等组成. 测试原理为由照到样品纳秒 激光产生的瞬态光电压信号经存储示波器的放大、 数据采集和信号处理后得到瞬态光电压谱.

\section{3 结果和讨论}

图 1 为纯 $\mathrm{TiO}_{2}$ 和 $\mathrm{TiO}_{2}-\mathrm{Sn} x \%$ 样品的 $\mathrm{XRD}$ 谱. $\mathrm{TiO}_{2}$ 为四方晶系锐钛矿型结构, 对于 $\mathrm{TiO}_{2}-\mathrm{Sn} x \%$ 样 品, 当掺入 $\mathrm{Sn}^{4+}$ 离子的浓度较低时, 如, $\mathrm{TiO}_{2}-\mathrm{Sn} 5 \%$, 其晶相结构主要为锐钛矿 $\mathrm{TiO}_{2}$, 同时伴有微量的金 红石型 $\mathrm{SnO}_{2}$ (33.95 衍射峰)和金红石型 $\mathrm{TiO}_{2}$ (27.15 衍射峰)生成. 另外, $\mathrm{TiO}_{2}-\mathrm{Sn} 5 \%$ 样品的各衍射峰相对 纯 $\mathrm{TiO}_{2}$ 出现小角移动(见图 1 插图), 而晶格常数和晶 胞体积相对纯 $\mathrm{TiO}_{2}$ 增大, 表明 $\mathrm{Sn}^{4+}$ 离子主要是以取 代式掺杂的形式存在. 因为 $\mathrm{Sn}^{4+}$ 的离子半径 $(69 \mathrm{pm})$ 与 $\mathrm{Ti}^{4+}$ 的离子半径 $(53 \mathrm{pm})^{18}$ 较接近, $\mathrm{Sn}^{4+}$ 离子能够占

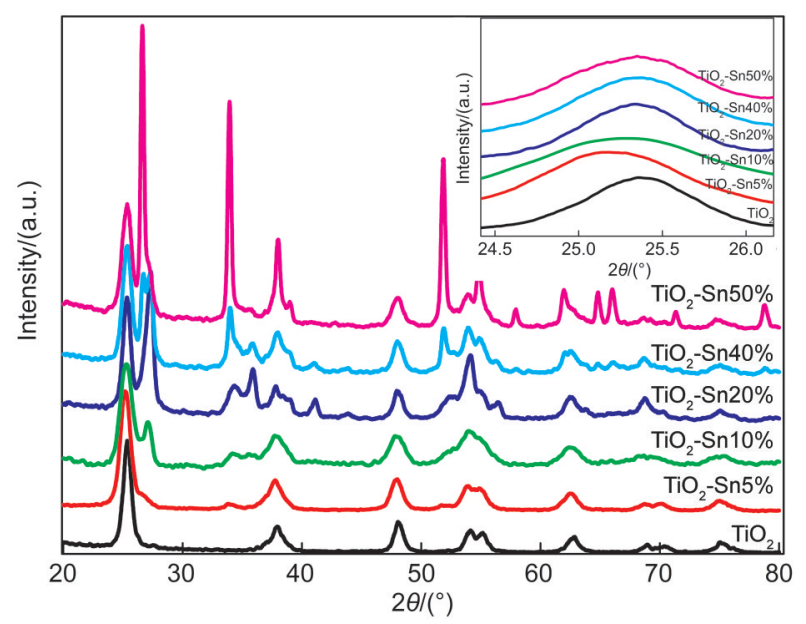

图 1 纯 $\mathrm{TiO}_{2}$ 和 $\mathrm{TiO}_{2}-\mathrm{Snx} \%$ 样品的 XRD 谱

Fig.1 XRD patterns of pure $\mathrm{TiO}_{2}$ and $\mathrm{TiO}_{2}-\mathrm{Sn} x \%$ samples Inset is the enlarged diffraction peaks located at around $25.3^{\circ}$, $x \%$ in $\mathrm{TiO}_{2}$-Sn $x \%$ represented the nominal molar percentage of $\mathrm{Sn}^{4+}$ ions in the $\mathrm{Sn}^{4+}$ and $\mathrm{Ti}^{4+}$ ions.

据 $\mathrm{TiO}_{2}$ 晶格中 $\mathrm{Ti}^{4+}$ 离子的晶格位置, 形成取代式掺 杂结构. 由于 $\mathrm{Sn}^{4+}$ 的离子半径 $(69 \mathrm{pm})$ 略大于 $\mathrm{Ti}^{4+}$ 离子 半径(53 pm), 导致了 $\mathrm{TiO}_{2}-\mathrm{Sn} 5 \%$ 样品晶胞参数和晶 胞体积相对纯 $\mathrm{TiO}_{2}$ 增大, 使 $\mathrm{TiO}_{2}-\mathrm{Sn} 5 \%$ 各衍射峰产 生小角移动. 随着 $\mathrm{Sn}^{4+}$ 离子浓度逐渐增加 $\left(\mathrm{TiO}_{2}\right.$ $\mathrm{Sn} 10 \%$ 至 $\mathrm{TiO}_{2}-\mathrm{Sn} 50 \%$ ), 在 $\mathrm{TiO}_{2}-\mathrm{Sn} x \%$ 样品中除锐钛 矿型 $\mathrm{TiO}_{2}$ 衍射峰外, 金红石型 $\mathrm{TiO}_{2}$ (110)和(101) 晶 面的衍射峰 $\left(27.15^{\circ}\right.$ 和 $\left.40.95^{\circ}\right)$ 和金红石型 $\mathrm{SnO}_{2}(110)$ 和(101)晶面的衍射峰 $\left(26.61^{\circ}\right.$ 和 $33.95^{\circ}$ ) 逐渐增强(与 $\mathrm{TiO}_{2}$ 锐钛矿衍射峰高比), 表明 $\mathrm{TiO}_{2}-\mathrm{Sn} x \%$ 逐渐形成 锐钛矿型 $\mathrm{TiO}_{2}$ 、金红石型 $\mathrm{TiO}_{2}$ 和金红石型 $\mathrm{SnO}_{2}$ 的复 合结构. 另外, 在 $\mathrm{TiO}_{2}-\mathrm{Sn} x \%$ 样品中 $\left(\mathrm{Sn}^{4+}\right.$ 离子浓度大 于 5\%), 随着 $\mathrm{Sn}^{4+}$ 离子浓度的增加, 锐钛矿 $\mathrm{TiO}_{2}$ 衍射 峰由大角逐渐向小角移动 (见图 1 插图), 其晶格常 数和晶胞体积相对 $\mathrm{TiO}_{2}-\mathrm{Sn} 5 \%$ 减小 (表 1), 表明取代 式掺杂的 $\mathrm{Sn}^{4+}$ 离子逐渐减少, 掺入的 $\mathrm{Sn}^{4+}$ 离子主要 生成金红石型 $\mathrm{SnO}_{2}$; 当 $\mathrm{Sn}^{4+}$ 离子浓度达到 $50 \%$ 时

表 1 样品的晶粒尺寸, 晶相含量和晶胞参数

Table 1 Crystallite size, phase contents, and cell parameters of the samples

\begin{tabular}{|c|c|c|c|c|c|c|}
\hline \multirow{2}{*}{ Sample } & \multicolumn{2}{|c|}{ Cell parameter/nm } & \multirow{2}{*}{$V_{\text {cell }} / \mathrm{nm}^{3}$} & \multicolumn{3}{|c|}{ Crystal size/nm } \\
\hline & $a=b$ & $c$ & & $\mathrm{~A}$ & $\mathrm{R}$ & S \\
\hline $\mathrm{TiO}_{2}$ & 0.3786 & 0.9499 & 0.13616 & 10.4 & & \\
\hline $\mathrm{TiO}_{2}-\mathrm{Sn} 5 \%$ & 0.3800 & 0.9742 & 0.14067 & 9.2 & & \\
\hline $\mathrm{TiO}_{2}-\mathrm{Sn} 10 \%$ & 0.3792 & 0.9620 & 0.13833 & 10.0 & & \\
\hline $\mathrm{TiO}_{2}-\mathrm{Sn} 20 \%$ & 0.3788 & 0.9560 & 0.13718 & 10.2 & 12.3 & \\
\hline $\mathrm{TiO}_{2}-\mathrm{Sn} 40 \%$ & 0.3786 & 0.9530 & 0.13662 & 10.6 & 17.9 & 30.1 \\
\hline $\mathrm{TiO}_{2}-\mathrm{Sn} 50 \%$ & 0.3786 & 0.9495 & 0.13610 & 10.9 & & 41.8 \\
\hline
\end{tabular}

The cell parameters are calculated by using the value of (101) and (110) diffraction peaks. A, R, and S denote anatase $\mathrm{TiO}_{2}$, rutile $\mathrm{TiO}_{2}$, and rutile $\mathrm{SnO}_{2}$, respectively. 
$\left(\mathrm{TiO}_{2}-\mathrm{Sn} 50 \%\right)$, 锐钛矿 $\mathrm{TiO}_{2}$ 衍射峰已移动到与纯 $\mathrm{TiO}_{2}$ 接近(见图 1 插图), 而晶格常数和晶胞体积与纯 $\mathrm{TiO}_{2}$ 相同, 表明 $\mathrm{TiO}_{2}-\mathrm{Sn} 50 \%$ 样品已形成 $\mathrm{TiO}_{2} / \mathrm{SnO}_{2}$ 复合结构. 以上过程机理为 $\mathrm{Sn}^{4+}$ 离子掺入大于一定 浓度时, 在催化剂的制备过程中, $\mathrm{TiO}_{2}$ 表面形成金 红石型 $\mathrm{SnO}_{2}$ 的条件占主导, 抑制了 $\mathrm{Sn}^{4+}$ 离子的取代 式掺杂, 同时诱导取代式掺杂的 $\mathrm{Sn}^{4+}$ 离子从 $\mathrm{TiO}_{2}$ 晶 格中析出形成 $\mathrm{SnO}_{2}$; 随着 $\mathrm{Sn}^{4+}$ 离子浓度的增加, 金 红石型 $\mathrm{SnO}_{2}$ 含量增加, 并诱导部分的金红石 $\mathrm{TiO}_{2}$ 在表面形成. 对于 $\mathrm{TiO}_{2}-\mathrm{Sn} x \%$ 样品, $\mathrm{Sn}^{4+}$ 离子低浓度 掺杂(如: $\mathrm{TiO}_{2}-\mathrm{Sn} 5 \%$ ) 形成取代式掺杂结构 $\left(\mathrm{Ti}_{1-x} \mathrm{~S}-\right.$ $\mathrm{n}_{x} \mathrm{O}_{2}$ ), $\mathrm{Sn}^{4+}$ 离子高浓度掺杂 (如: $\mathrm{TiO}_{2}-\mathrm{Sn} 50 \%$ ) 形成 $\mathrm{TiO}_{2}$ 和 $\mathrm{SnO}_{2}$ 的复合结构 $\left(\mathrm{TiO}_{2} / \mathrm{SnO}_{2}\right)$ 的结论将由 XPS 谱进一步的证明.

图 2 为 $\mathrm{TiO}_{2}-\mathrm{Sn} 5 \%$ 和 $\mathrm{TiO}_{2}-\mathrm{Sn} 50 \%$ 的 $\mathrm{Sn} 2 p$ 的 XPS 谱. 在 $\mathrm{TiO}_{2}-\mathrm{Sn} 5 \%$ (曲线 a) 中, 掺杂 $\mathrm{Sn}$ 的 $\mathrm{Sn} 2 p_{3 / 2}$ 的结合能 $(486.0 \mathrm{eV})$ 低于 $\mathrm{SnO}_{2}$ 的 $\mathrm{Sn} 2 p_{3 / 2}$ 的结合能 $(486.5 \mathrm{eV}){ }^{19}$ 而高于金属 $\mathrm{Sn}$ 中 $\mathrm{Sn} 2 p_{3 / 2}$ 结合能(484.6 $\mathrm{eV})$, 表明 $\mathrm{TiO}_{2}-\mathrm{Sn} 5 \%$ 中的 $\mathrm{Sn}^{4+}$ 离子取代了锐钛矿 $\mathrm{TiO}_{2}$ 中晶格 $\mathrm{Ti}^{4+}$ 离子位置, 形成 $\mathrm{Ti}-\mathrm{O}-\mathrm{Sn}(\mathrm{O}$ 周围两 个 $\mathrm{Ti}$ 和一个 $\mathrm{Sn}$ 离子配位) 取代式掺杂结构. 因为取 代式掺杂结构 $\mathrm{Ti}-\mathrm{O}-\mathrm{Sn}$ 与 $\mathrm{SnO}_{2}$ 中 $\mathrm{Sn}-\mathrm{O}-\mathrm{Sn}(\mathrm{O}$ 周围三个 $\mathrm{Sn}$ 离子配位) 结构相比, $\mathrm{Ti}$ 的电负性(1.54) 小于 $\mathrm{Sn}(1.96){ }^{20}$ 使 $\mathrm{Ti}-\mathrm{O}-\mathrm{Sn}$ 中 $\mathrm{Sn} 2 p_{3 / 2}$ 结合能 $(486.0 \mathrm{eV})$ 低于 $\mathrm{SnO}_{2}$ 的 $\mathrm{Sn} 2 p_{3 / 2}$ 的结合能 $(486.5 \mathrm{eV})$; 取代式掺杂结构 $\mathrm{Ti}-\mathrm{O}-\mathrm{Sn}$ 与金属 $\mathrm{Sn}$ 相比, $\mathrm{Sn}^{4+}$ 离 子周围的 $\mathrm{O}$ 的电负性(3.50)大于 $\mathrm{Sn}$ (1.96), 导致 $\mathrm{Ti}-$ $\mathrm{O}-\mathrm{Sn}$ 结构中 $\mathrm{Sn} 2 p_{3 / 2}$ 结合能 $(486.0 \mathrm{eV})$ 高于金属 $\mathrm{Sn}$ 中 $\mathrm{Sn} 2 p_{3 / 2}$ 的结合能 $\left(486.4 \mathrm{eV}\right.$ ). 在 $\mathrm{TiO}_{2}-\mathrm{Sn} 50 \%$ (曲线 b)中, 掺杂 $\mathrm{Sn}$ 的 $\mathrm{Sn} 2 p_{3 / 2}(486.45 \mathrm{eV})$ 与 $\mathrm{SnO}_{2}$ 的 $\mathrm{Sn} 2 p_{3 / 2}$

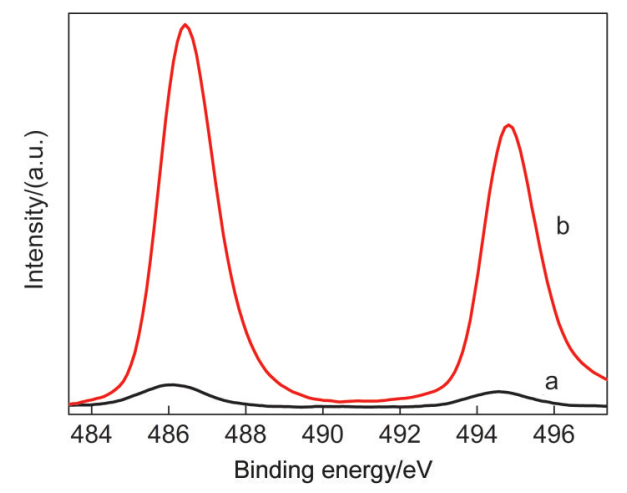

图 $2 \mathrm{TiO}_{2}-\mathrm{Sn5} \%$ (a) 和 $\mathrm{TiO}_{2}-\mathrm{Sn} 50 \%$ (b) 的 $\mathrm{Sn} 2 p$ 的 XPS 谱

Fig.2 XPS spectra of $\mathrm{Sn} 2 p$ for $\mathrm{TiO}_{2}-\mathrm{Sn} 5 \%$ (a) and $\mathrm{TiO}_{2}-\mathrm{Sn50} \%$ (b)

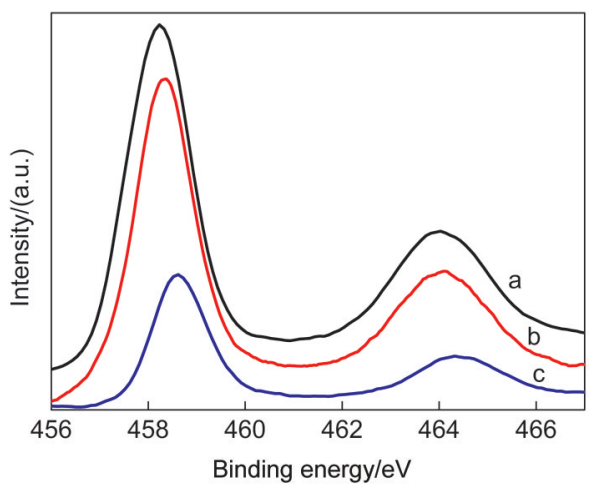

图 $3 \mathrm{TiO}_{2}(\mathrm{a}), \mathrm{TiO}_{2}-\mathrm{Sn} 5 \%(\mathrm{~b})$ 和 $\mathrm{TiO}_{2}-\mathrm{Sn} 50 \%$ (c) 的 $\mathrm{Ti} 2 p$ 的 XPS 谱

Fig.3 XPS spectra of Ti $2 p$ for $\mathrm{TiO}_{2}$ (a), $\mathrm{TiO}_{2}-\mathrm{Sn5} \%$ (b), and $\mathrm{TiO}_{2}-\mathrm{Sn} 50 \%$ (c)

峰位基本一致 $\left(\mathrm{SnO}_{2}\right.$ 的 $\mathrm{Sn} 2 p_{3 / 2}$ 结合能为 $\left.486.5 \mathrm{eV}\right)$, 表明 $\mathrm{TiO}_{2}-\mathrm{Sn} 50 \%$ 样品中掺入的 $\mathrm{Sn}^{4+}$ 离子主要以 $\mathrm{SnO}_{2}$ 的形式存在. 图 3 为纯 $\mathrm{TiO}_{2} 、 \mathrm{TiO}_{2}-\mathrm{Sn} 5 \%$ 和 $\mathrm{TiO}_{2-}$ $\mathrm{Sn} 50 \%$ 的 Ti $2 p$ 的 XPS 谱. 纯 $\mathrm{TiO}_{2}$ (曲线 a) 的 Ti $2 p_{3 / 2}$ 和 Ti $2 p_{1 / 2}$ 峰的结合能分别为 458.2 和 $464.0 \mathrm{eV}$. 与纯 $\mathrm{TiO}_{2}$ 比较, $\mathrm{TiO}_{2}-\mathrm{Sn} 5 \%$ (曲线 $\mathrm{b}$ ) 和 $\mathrm{TiO}_{2}-\mathrm{Sn} 50 \%$ (曲线 c)的 Ti $2 p$ 峰的结合能增加, 意味着与掺杂 $\mathrm{Sn}$ 离子的 状态相关. 对于 $\mathrm{TiO}_{2}-\mathrm{Sn} 5 \%$, 由于 $\mathrm{Sn}^{4+}$ 离子取代 $\mathrm{TiO}_{2}$ 中晶格 $\mathrm{Ti}^{4+}$ 离子(取代式掺杂)形成的 $\mathrm{Ti}-\mathrm{O}-\mathrm{Sn}$ 结 构; 与纯 $\mathrm{TiO}_{2}$ 中 $\mathrm{Ti}-\mathrm{O}-\mathrm{Ti}$ 相比, $\mathrm{Ti}-\mathrm{O}-\mathrm{Sn}$ 中 $\mathrm{Sn}$ 的 电负性大于 $\mathrm{Ti}^{4+}$ 离子, 使 $\mathrm{TiO}_{2}-\mathrm{Sn} 5 \%$ 的 $\mathrm{Ti} 2 p$ 结合能 向高位移动 (458.3 和 $464.1 \mathrm{eV}$ ). 对于 $\mathrm{TiO}_{2}-\mathrm{Sn} 50 \%$, 掺入的 $\mathrm{Sn}^{4+}$ 离子形成 $\mathrm{SnO}_{2}$ 团簇, 并与 $\mathrm{TiO}_{2}$ 团簇以 $\mathrm{Sn}-\mathrm{O}-\mathrm{Ti}$ 的形式链接 $\left(\mathrm{TiO}_{2} / \mathrm{SnO}_{2}\right.$ 复合结构 $)$, 与纯 $\mathrm{TiO}_{2}$ 中 $\mathrm{Ti}-\mathrm{O}-\mathrm{Ti}$ 相比, $\mathrm{Sn}$ 的电负性大于 $\mathrm{Ti}$, 使 $\mathrm{TiO}_{2}-\mathrm{Sn} 50 \%$ 的 Ti $2 p$ 结合能提高为 (458.6 和 464.4 $\mathrm{eV})$. 图 4 为纯 $\mathrm{TiO}_{2} 、 \mathrm{TiO}_{2}-\mathrm{Sn} 5 \%$ 和 $\mathrm{TiO}_{2}-\mathrm{Sn} 50 \%$ 的 $\mathrm{O} 1 \mathrm{~s}$

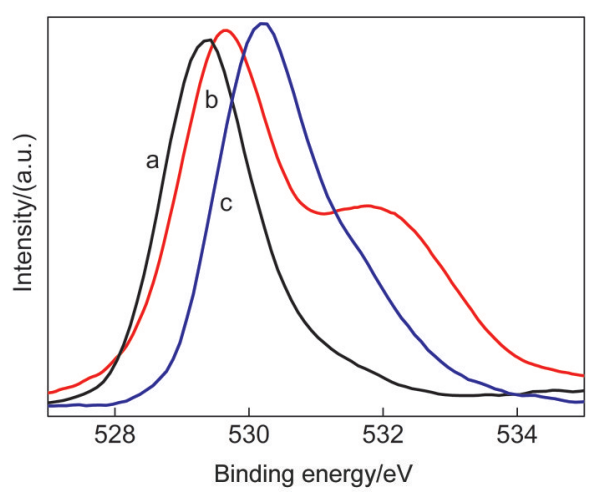

图 $4 \mathrm{TiO}_{2}(\mathrm{a}), \mathrm{TiO}_{2}-\mathrm{Sn} 5 \%(\mathrm{~b})$ 和 $\mathrm{TiO}_{2}-\mathrm{Sn} 50 \%(\mathrm{c})$ 的 $\mathrm{O} 1 s$ 的 XPS 谱

Fig.4 XPS spectra of $\mathrm{O} 1 s$ for $\mathrm{TiO}_{2}$ (a), $\mathrm{TiO}_{2}-\mathrm{Sn} 5 \%$ (b), and $\mathrm{TiO}_{2}-\mathrm{Sn} 50 \%$ (c) 
的 XPS 谱. 结合能为 529.4 和 $531.1 \mathrm{eV}$ 附近的响应峰 分别为纯 $\mathrm{TiO}_{2}$ (曲线 $\mathrm{a}$ )晶格氧 $\mathrm{O} 1 \mathrm{~s}$ 和表面氧物种(主 要为表面羟基 $-\mathrm{OH}$ 和表面桥氧 $-\mathrm{O}-)^{21,22}$ 与纯 $\mathrm{TiO}_{2}$ (曲线 a) 比较, $\mathrm{TiO}_{2}-\mathrm{Sn} 5 \%$ (曲线 b) 和 $\mathrm{TiO}_{2}-$ $\mathrm{Sn} 50 \%$ (曲线 $\mathrm{c}$ )的晶格氧 $\mathrm{O} 1 \mathrm{~s}$ 峰的结合能增加主要 源于 $\mathrm{Sn}^{4+}$ 离子的掺杂态. 对于 $\mathrm{TiO}_{2}-\mathrm{Sn} 5 \%, \mathrm{Sn}^{4+}$ 离子 取代晶格 $\mathrm{Ti}^{4+}$ 离子形成 $\mathrm{Ti}-\mathrm{O}-\mathrm{Sn}$ 取代式掺杂结构, 与纯 $\mathrm{TiO}_{2}$ 中 $\mathrm{Ti}-\mathrm{O}-\mathrm{Ti}$ 相比, $\mathrm{O}$ 周围的 $\mathrm{Sn}$ 的电负性 大于 $\mathrm{Ti}$, 使 $\mathrm{TiO}_{2}-\mathrm{Sn} 5 \%$ 的 $\mathrm{O} 1 \mathrm{~s}$ 结合能向高位移动 $(529.7 \mathrm{eV})$; 而 $\mathrm{TiO}_{2}-\mathrm{Sn} 50 \%$ 晶格氧的结合能为 530.2 $\mathrm{eV}$, 已接近 $\mathrm{SnO}_{2}$ 晶格氧 $\mathrm{O} 1 s$ 的结合能 $(530.5 \mathrm{eV}),{ }^{16}$ 表明在 $\mathrm{TiO}_{2}-\mathrm{Sn} 50 \%$ 样品中掺入的 $\mathrm{Sn}^{4+}$ 离子已形成 $\mathrm{SnO}_{2}$. 另外, 在 $\mathrm{TiO}_{2}-\mathrm{Sn} 5 \%$ (曲线 b) 中, 表面物种的 $\mathrm{O}$ $1 s$ 的峰 $\left(531.1 \mathrm{eV}\right.$ ) 相对纯 $\mathrm{TiO}_{2}$ (曲线 a) 和 $\mathrm{TiO}_{2}-$ $\mathrm{Sn} 50 \%$ (曲线 c)增强, 表明 $\mathrm{TiO}_{2}-\mathrm{Sn} 5 \%$ 样品表面羟基 $(-\mathrm{OH})$ 和表面桥氧 $(-\mathrm{O}-)$ 含量大于纯 $\mathrm{TiO}_{2}$ 和 $\mathrm{TiO}_{2}-\mathrm{Sn} 50 \%$.

由 XRD 和 XPS 结果可以证明, 当掺入 $\mathrm{Sn}^{4+}$ 离子 的浓度较低时(如, $\mathrm{TiO}_{2}-\mathrm{Sn} 5 \%$ ), $\mathrm{Sn}^{4+}$ 离子主要是以取 代的方式占据 $\mathrm{TiO}_{2}$ 晶格中 $\mathrm{Ti}^{4+}$ 离子的位置, 形成取 代式掺杂结构 $\left(\mathrm{Ti}_{1-x} \mathrm{Sn}_{x} \mathrm{O}_{2}\right)$. 当掺入 $\mathrm{Sn}^{4+}$ 离子的浓度较 高时(如, $\mathrm{TiO}_{2}-\mathrm{Sn} 50 \%$ ), $\mathrm{Sn}^{4+}$ 离子主要形成金红石 $\mathrm{SnO}_{2}$, 同时伴有金红石型 $\mathrm{TiO}_{2}$ 生成, 形成 $\mathrm{TiO}_{2}$ 和 $\mathrm{SnO}_{2}$ 的复合结构 $\left(\mathrm{TiO}_{2} / \mathrm{SnO}_{2}\right)$.

图 5 为纯 $\mathrm{TiO}_{2} 、 \mathrm{TiO}_{2}-\mathrm{Sn} 5 \%$ 和 $\mathrm{TiO}_{2}-\mathrm{Sn} 50 \%$ 的样品 的 SPS 谱. 在 $336 \mathrm{~nm}$ 附近的强峰为纯 $\mathrm{TiO}_{2}$ 带一带跃 迁 (曲线a), 起峰阈值为 $375.0 \mathrm{~nm}$, 其禁带宽度为 $3.31 \mathrm{eV} . \mathrm{TiO}_{2}-\mathrm{Sn} 5 \%$ 样品 (曲线b) 的带一带跃迁峰

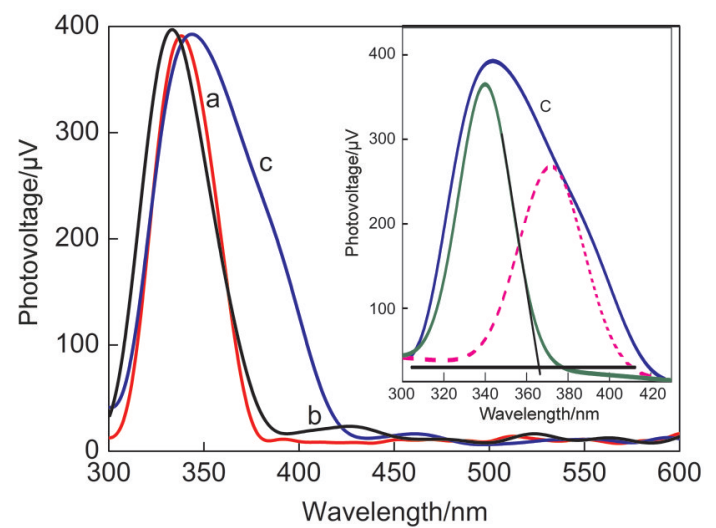

图 $5 \mathrm{TiO}_{2}(\mathrm{a}), \mathrm{TiO}_{2}-\mathrm{Sn} 5 \%$ (b) 和 $\mathrm{TiO}_{2}-\mathrm{Sn} 50 \%$ (c) 的表面 光电压谱

Fig.5 SPS spectra for $\mathrm{TiO}_{2}(\mathrm{a}), \mathrm{TiO}_{2}-\mathrm{Sn} 5 \%$ (b), and $\mathrm{TiO}_{2}-\mathrm{Sn50} \%$ (c)

Insert is the fitting curves of $\mathrm{TiO}_{2}-\mathrm{Sn} 50 \%$ (curve c). The solid line and dashed line represent the two peaks after fitting curve $\mathrm{c}$.
(338 nm) 的起峰阈值为 $378.0 \mathrm{~nm}$, 其禁带宽度为 $3.29 \mathrm{eV}$. 在 $426.0 \mathrm{~nm}$ 附近弱的响应峰为 $\mathrm{TiO}_{2}-\mathrm{Sn} 5 \%$ 的价带到 $\mathrm{Sn}^{4+}$ 离子掺杂能级的跃迁, ${ }^{18}$ 该掺杂能级在 导带下 $0.38 \mathrm{eV}$. 对于 $\mathrm{TiO}_{2}-\mathrm{Sn} 50 \%$ 样品(曲线 $\mathrm{c}$ ), 拟合 后分为两个峰 (见插图), $340.0 \mathrm{~nm}$ 响应峰为 $\mathrm{TiO}_{2}-\mathrm{Sn} 50 \%$ 样品中 $\mathrm{TiO}_{2}$ 的带-带跃迁, 起峰阈值为 $368.0 \mathrm{~nm}$, 禁带宽度为 $3.36 \mathrm{eV}$. 另一个强峰在 372.2 $\mathrm{nm}$ 为 $\mathrm{TiO}_{2}-\mathrm{Sn} 50 \%$ 样品中 $\mathrm{TiO}_{2}$ 的价带到 $\mathrm{SnO}_{2}$ 的导 带的跃迁, 起峰阈值为 $420.0 \mathrm{~nm}$, 计算可得 $\mathrm{SnO}_{2}$ 的 导带在 $\mathrm{TiO}_{2}$ 导带下 $0.33 \mathrm{eV}$.

图 6 为纯 $\mathrm{TiO}_{2}, \mathrm{TiO}_{2}-\mathrm{Sn} 5 \%$ 和 $\mathrm{TiO}_{2}-\mathrm{Sn} 50 \%$ 的样品 的光致发光谱. 纯 $\mathrm{TiO}_{2}$ (曲线 a) 分别在 $480 \mathrm{~nm}$ 和 $525 \mathrm{~nm}$ 有两个苂光峰, 分别对应于捕获一个电子和 两个电子的氧空位能级到 $\mathrm{TiO}_{2}$ 价带的跃迁, 氧空位 能级分别位于导带下 0.51 和 $0.82 \mathrm{eV}$ 处. ${ }^{23,24}$ 由于氧 空位能级的存在, 导带的光生电子通过无辐射跃迁 方式到达氧空位能级, 然后与 $\mathrm{TiO}_{2}$ 价带的光生空穴 复合发光. 与纯 $\mathrm{TiO}_{2}$ 比较, $\mathrm{TiO}_{2}-\mathrm{Sn} 5 \%$ (曲线 b) 样品 的 $\mathrm{Sn}^{4+}$ 离子掺杂能级位于导带下 $0.38 \mathrm{eV}$ 处, 且在氧 空位能级 (导带下方 0.51 和 $0.82 \mathrm{eV}$ )之上, 所以导带 的光生电子能够转移到 $\mathrm{Sn}^{4+}$ 离子掺杂能级, 然后达 到粒子表面, 促进了光生载流子的分离, 使得光生 电子从氧空位能级到价带的复合几率降低, 苂光强 度减弱; 对于 $\mathrm{TiO}_{2}-\mathrm{Sn} 50 \%$ (曲线 c), 由于 $\mathrm{SnO}_{2}$ 和 $\mathrm{TiO}_{2}$ 形成复合结构, $\mathrm{SnO}_{2}$ 的导带低于 $\mathrm{TiO}_{2}$ 导带, 且高于 $\mathrm{TiO}_{2}$ 的氧空位能级 (导带下方 0.51 和 $0.82 \mathrm{eV}$ ), 所以 $\mathrm{TiO}_{2}$ 导带的光生电子能够转移到 $\mathrm{SnO}_{2}$ 的导带, 促进 了光生载流子的分离, 从而抑制了 $\mathrm{TiO}_{2}$ 氧空位能级 的光生电子与价带光生空穴的复合, 导致了苂光强 度的降低.

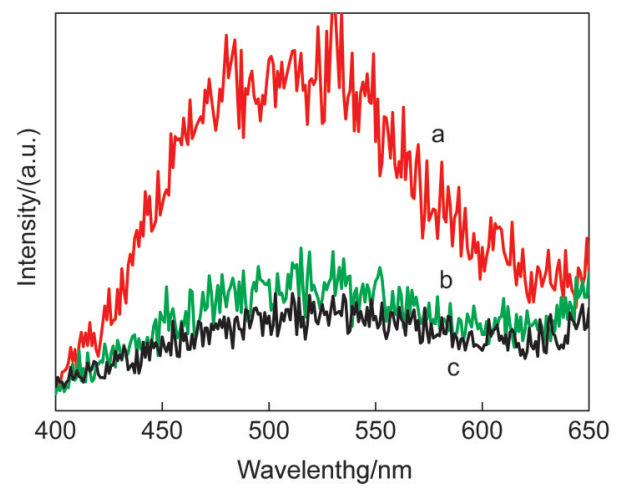

图 $6 \mathrm{TiO}_{2}(\mathrm{a}), \mathrm{TiO}_{2}-\mathrm{Sn} 5 \%$ (b) 和 $\mathrm{TiO}_{2}-\mathrm{Sn} 50 \%$ (c) 的光致 发光谱

Fig.6 Photoluminescence spectra of $\mathrm{TiO}_{2}(\mathrm{a}), \mathrm{TiO}_{2}-\mathrm{Sn5} \%$ (b) and $\mathrm{TiO}_{2}-\mathrm{Sn50} \%$ (c) 


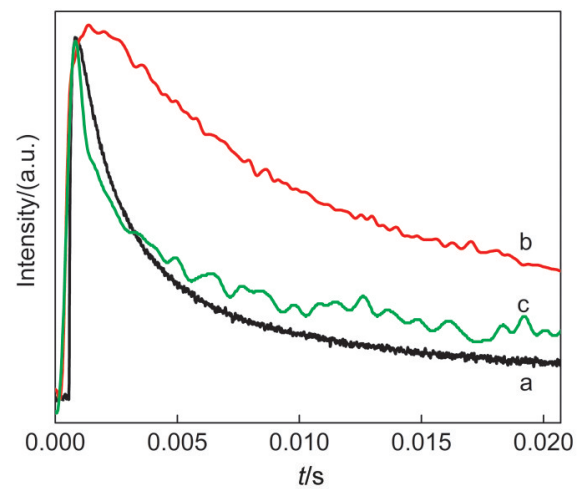

图 $7 \mathrm{TiO}_{2}(\mathrm{a}), \mathrm{TiO}_{2}-\mathrm{Sn} 5 \%(\mathrm{~b})$, 和 $\mathrm{TiO}_{2}-\mathrm{Sn} 50 \%$ (c) 的瞬态 光电压谱

Fig.7 Transient photovoltage spectra of $\mathrm{TiO}_{2}$ (a), $\mathrm{TiO}_{2}-\mathrm{Sn} 5 \%$ (b), and $\mathrm{TiO}_{2}-\mathrm{Sn} 50 \%$ (c)

图 7 为纯 $\mathrm{TiO}_{2}$ (曲线 $\mathrm{a}$ )、 $\mathrm{TiO}_{2}-\mathrm{Sn} 5 \%$ (曲线 $\mathrm{b}$ ) 和 $\mathrm{TiO}_{2}-\mathrm{Sn} 50 \%$ (曲线 $\mathrm{c}$ )样品的瞬态光电压谱(激发光波 长 $340 \mathrm{~nm}$ ). 在图 7 中, 瞬态光电压谱的起峰过程(如 纯 $\mathrm{TiO}_{2}$, 约为 0.0002-0.0008 s) 对应于光生载流子的 分离过程, 其机理为样品在 $340 \mathrm{~nm}$ 激光的照射下产 生带-带跃迁, 光生电子沿着导带转移到表面, 而光 生空穴沿着价带流向体相, 导致光生载流子分离, 产生光电压响应. 瞬态光电压谱峰的回落过程(如纯 $\mathrm{TiO}_{2}$, 约为 $0.0008-0.02 \mathrm{~s}$ ) 为光生载流子的复合过 程, 光电压响应随之衰灭 ${ }^{25}$ 由双指数衰减对瞬态光 电压谱曲线拟合处理后, 每一个瞬态光电压谱曲线 都呈现出两个光生载流子复合过程, 其延迟时间为 $\tau_{1}$ 和 $\tau_{2}$ (表 2), 如 $\mathrm{TiO}_{2}, \tau_{1}$ 为表面的光生电子由导带通 过表面态能级与价带光生空穴复合的延迟时间; $\tau_{2}$ 为表面的光生电子由导带转移到氧空位能级, 然后 再与价带光生空穴复合的延迟时间. 结果表明(表 2), 三个样品的光生载流子的复合过程的延迟时间 $\tau_{1}$ 和 $\tau_{2}$ 遵从 $\mathrm{TiO}_{2}-\mathrm{Sn} 5 \%>\mathrm{TiO}_{2}-\mathrm{Sn} 50 \%>$ 纯 $\mathrm{TiO}_{2}$ 的规律. 对于 $\mathrm{TiO}_{2}-\mathrm{Sn} 50 \%$ 样品, 由于 $\mathrm{SnO}_{2}$ 和 $\mathrm{TiO}_{2}$ 形成复合结 构 $\left(\mathrm{TiO}_{2} / \mathrm{SnO}_{2}\right), \mathrm{SnO}_{2}$ 的导带低于 $\mathrm{TiO}_{2}$ 导带 $0.33 \mathrm{eV}$, 能够使跃迁到 $\mathrm{TiO}_{2}$ 导带的光生电子转移到 $\mathrm{SnO}_{2}$ 导 带, 产生光生载流子分离(产生光电压信号); 然而, 与纯 $\mathrm{TiO}_{2}$ 相比, $\mathrm{TiO}_{2} / \mathrm{SnO}_{2}$ 界面态能级相对较多, 而 且存在界面势能, $\mathrm{SnO}_{2}$ 导带的光生电子经由界面态 能级与价带光生空穴复合或 $\mathrm{SnO}_{2}$ 导带的光生电子 穿越 $\mathrm{TiO}_{2} / \mathrm{SnO}_{2}$ 界面转移到 $\mathrm{TiO}_{2}$ 氧空位能级与价带 光生空穴复合相对困难, 所以 $\mathrm{TiO}_{2}-\mathrm{Sn} 50 \%$ 样品的延 迟时间 $\tau_{1}$ 和 $\tau_{2}$ 大于纯 $\mathrm{TiO}_{2}$. 对于 $\mathrm{TiO}_{2}-\mathrm{Sn} 5 \%$ 样品, 由 于 $\mathrm{Sn}^{4+}$ 离子的掺杂能级在导带下 $0.38 \mathrm{eV}$, 跃迁到导 带的光生电子能够经由 $\mathrm{Sn}^{4+}$ 离子的掺杂能级转移到
表 2 样品的瞬态光电压谱经双指数延迟拟合后的延迟 时间常数 $\tau_{1}$ 和 $\tau_{2}$

Table 2 Values of the calculated decay time constant $\tau_{1}$ and $\tau_{2}$ through double exponential decay fitting for the corresponding samples

\begin{tabular}{cccc}
\hline & $\mathrm{TiO}_{2}$ & $\mathrm{TiO}_{2}-\mathrm{Sn} 5 \%$ & $\mathrm{TiO}_{2}-\mathrm{Sn} 50 \%$ \\
\hline$\tau_{1} / \mathrm{s}$ & $0.00165 \pm 0.000008$ & $0.00817 \pm 0.000035$ & $0.00171 \pm 0.000036$ \\
$\tau_{2} / \mathrm{s}$ & $0.00844 \pm 0.000127$ & $0.58886 \pm 0.108640$ & $0.03417 \pm 0.000626$ \\
\hline
\end{tabular}

表面, 产生光生载流子分离(产生光电压信号); 然 而, 由于 $\mathrm{Sn}^{4+}$ 离子掺杂能级的光生电子转移到氧空 位能级的几率较小, 导致表面光生电子由 $\mathrm{Sn}^{4+}$ 离子 掺杂能级转移氧空位能级, 再与价带光生空穴复合 的几率减少; 另外, $\mathrm{Sn}^{4+}$ 离子的掺杂使样品产生更多 的表面态能级, 致使表面光生电子通过表面态能级 与价带光生空穴复合过程时间相对延迟, 所以 $\mathrm{TiO}_{2}-\mathrm{Sn} 5 \%$ 样品 $\tau_{1}$ 和 $\tau_{2}$ 过程的延迟时间大于 $\mathrm{TiO}_{2}-$ $\mathrm{Sn} 50 \%$ 和纯 $\mathrm{TiO}_{2}$. 光生载流子的复合过程的延迟时 间 $\tau_{1}$ 和 $\tau_{2}$ 的增加, 意味着光生载流子复合几率的降 低, 而分离效率提高, 因此, 三个样品的光生载流子 分离效率遵循 $\mathrm{TiO}_{2}-\mathrm{Sn} 5 \%>\mathrm{TiO}_{2}-\mathrm{Sn} 50 \%>$ 纯 $\mathrm{TiO}_{2}$ 的 规律.

图 8 为纯 $\mathrm{TiO}_{2} 、 \mathrm{TiO}_{2}-\mathrm{Sn} 5 \%$ 和 $\mathrm{TiO}_{2}-\mathrm{Sn} 50 \%$ 样品的 紫外光催化降解对氯苯酚的浓度与降解时间的关 系 $(c-t)$ 曲线, 其紫外光催化活性 (降解率 $\left(\Delta c / c_{0}\right.$ )、半 衰期 $\left(t_{1 / 2}\right)$ 和比活性) 见表 3. 结果表明, 空白实验中对 氯苯酚几乎没有光解. 纯 $\mathrm{TiO}_{2}$ 在 $60 \mathrm{~min}$ 降解率为 $20.6 \%$, 比光催化活性为 $0.152 \mathrm{mmol} \cdot \mathrm{g}^{-1} \cdot \mathrm{h}^{-1}$. $\mathrm{TiO}_{2-}$ $\mathrm{Sn} 50 \%$ 样品的紫外光催化活性高于纯 $\mathrm{TiO}_{2}$, 其中, $60 \mathrm{~min}$ 降解率为 $30.2 \%$, 比光催化活性为 0.224 $\mathrm{mmol} \cdot \mathrm{g}^{-1} \cdot \mathrm{h}^{-1}$. $\mathrm{TiO}_{2}-\mathrm{Sn} 5 \%$ 样品表现出最高的光催化

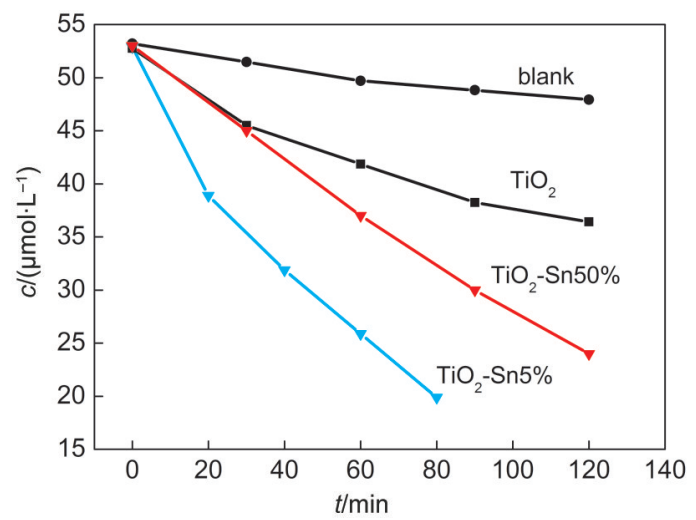

图 8 纯 $\mathrm{TiO}_{2} 、 \mathrm{TiO}_{2}-\mathrm{Sn} 5 \%$ 和 $\mathrm{TiO}_{2}-\mathrm{Sn} 50 \%$ 样品的紫外光催 化降解对氯苯酚的浓度一时间 $(c-t)$ 曲线

Fig.8 Concentration-time ( $c-t)$ curves of 4-chlorophenol for $\mathrm{TiO}_{2}, \mathrm{TiO}_{2}-\mathrm{Sn} 5 \%$, and $\mathrm{TiO}_{2}-\mathrm{Sn} 50 \%$ samples under ultraviolet irradiation 
表 3 紫外光照下对氯苯酚的光降解

Table 3 Photodegradation of 4-chlorophenol under ultraviolet irradiation

\begin{tabular}{cccrc}
\hline Sample & $\Delta c / c_{0}{ }^{\mathrm{a}}$ & $k / \mathrm{min}^{-1}$ & $t_{1 / 2} / \mathrm{min}$ & $\begin{array}{c}\text { Specific photocatalytic } \\
\text { acitivity } /\left(\mathrm{mmol} \cdot \mathrm{g}^{-1} \cdot \mathrm{h}^{-1}\right)^{\mathrm{b}}\end{array}$ \\
\hline $\mathrm{TiO}_{2}$ & $20.6 \%$ & $3.85 \times 10^{-3}$ & 180.0 & 0.152 \\
$\mathrm{TiO}_{2}-\mathrm{Sn} 5 \%$ & $51.9 \%$ & $1.22 \times 10^{-2}$ & 56.8 & 0.378 \\
$\mathrm{TiO}_{2}-\mathrm{Sn} 50 \%$ & $30.2 \%$ & $5.99 \times 10^{-3}$ & 115.0 & 0.224 \\
\hline
\end{tabular}

${ }^{\mathrm{a}}$ The degradation ratios of photocatalytic reaction at the first hour. ${ }^{\mathrm{b}} \mathrm{The}$ amount of degradated 4-chlorophenol per unit catalyst at the first hour photocatalytic reaction. $k$ : rate constant; $t_{1 / 2}$ : half time

活性, $60 \mathrm{~min}$ 降解率为 $51.5 \%$, 比光催化活性为 0.378 $\mathrm{mmol} \cdot \mathrm{g}^{-1} \cdot \mathrm{h}^{-1}$, 大约是纯 $\mathrm{TiO}_{2}$ 的 2.5 倍. 另外, 所有样 品的 $\ln \left(c_{0} / c\right)-t$ 之间呈现直线关系, 说明其光催化反 应为一级反应.

基于表征结果和光催化基本原理, $\mathrm{TiO}_{2}-\mathrm{Sn} 5 \%$ 和 $\mathrm{TiO}_{2}-\mathrm{Sn} 50 \%$ 样品的紫外光催化活性高于纯 $\mathrm{TiO}_{2}$ 的主要原因如下. 在紫外光催化过程中, 由于纯 $\mathrm{TiO}_{2}$ 的光生电子通过氧空位能级与价带空穴复合的几 率相对较高 (见苂光光谱, 图 6), 而且达到表面的光 生电子相对容易通过表面态能级或氧空位能级与 价带光生空穴复合, 其两个复合过程的延迟时间 $\tau_{1}$ 和 $\tau_{2}$ 相对较短 (瞬态光电压谱, 图 7), 表明光生载流 子的分离效率较低, 导致了较低的光催化活性. 与 纯 $\mathrm{TiO}_{2}$ 相比, 由于 $\mathrm{TiO}_{2}-\mathrm{Sn} 50 \%$ 样品以 $\mathrm{TiO}_{2} / \mathrm{SnO}_{2}$ 复 合结构存在, $\mathrm{SnO}_{2}$ 导带低于 $\mathrm{TiO}_{2}$ 导带 $0.33 \mathrm{eV}$, 有利 于 $\mathrm{TiO}_{2}$ 导带的光生电子转移到 $\mathrm{SnO}_{2}$ 导带, 产生光生 载流子分离, 而降低其复合几率; 另外, 由于 $\mathrm{TiO}_{2} /$ $\mathrm{SnO}_{2}$ 界面的存在, 使分离后的光生电子难于通过 $\mathrm{TiO}_{2}$ 氧空位能级或 $\mathrm{TiO}_{2} / \mathrm{SnO}_{2}$ 界面态能级与价带光 生空穴复合, 其延迟时间 $\tau_{1}$ 和 $\tau_{2}$ 大于纯 $\mathrm{TiO}_{2}$, 有效地 促进了光生载流子的分离; 此外, 在 $\mathrm{TiO}_{2} / \mathrm{SnO}_{2}$ 界面 $\mathrm{TiO}_{2}$ 价带到 $\mathrm{SnO}_{2}$ 导带的跃迁, 增加了光生载流子的 浓度和催化剂的光谱吸收范围; 因此, $\mathrm{TiO}_{2}-\mathrm{Sn} 50 \%$ 的紫外光催化活性高于纯 $\mathrm{TiO}_{2}$. 对于 $\mathrm{TiO}_{2}-\mathrm{Sn} 5 \%$ 样 品, 由于 $\mathrm{Sn}^{4}$ 掺杂能级在导带下 $0.38 \mathrm{eV}$, 光生电子能 够通过掺杂能级直接转移到催化剂的表面, 导致了 光生载流子的有效分离. 另外, $\mathrm{Sn}^{4+}$ 离子掺杂能级的 存在使表面光生电子转移到氧空位能级的几率减 小, 而且 $\mathrm{Sn}^{4+}$ 离子的掺杂使样品表面态能级增加, 有 效地阻止了表面的光生电子通过氧空位能级或表 面态能级与价带光生空穴复合, 其延迟时间 $\tau_{1}$ 和 $\tau_{2}$ 大 于纯 $\mathrm{TiO}_{2}$ 和 $\mathrm{TiO}_{2}-\mathrm{Sn} 50 \%$ 的延迟时间, 意味着光生载 流子的分离效率得到了有效的提高, 光生载流子参 加光催化反应的几率增大; 此外, $\mathrm{TiO}_{2}-\mathrm{Sn} 5 \%$ 的价带
到 $\mathrm{Sn}^{4+}$ 离子掺杂能级的跃迁, 导致了光生载流子的 浓度和催化剂的吸收范围增加; 因此, $\mathrm{TiO}_{2}-\mathrm{Sn} 5 \%$ 催 化剂紫外光催化活性高于纯 $\mathrm{TiO}_{2}$ 和 $\mathrm{TiO}_{2}-\mathrm{Sn} 50 \%$.

\section{4 结 论}

采用溶胶-凝胶法制备出纯 $\mathrm{TiO}_{2}$ 和不同 $\mathrm{Sn}^{4+}$ 离 子浓度掺杂的 $\mathrm{TiO}_{2}-\mathrm{Sn} x \%$ 催化剂. 当 $\mathrm{Sn}^{4+}$ 离子浓度较 低时 $\left(\mathrm{TiO}_{2}-\mathrm{Sn} 5 \%\right), \mathrm{Sn}^{4+}$ 离子是以取代式掺杂的方式 存在于 $\mathrm{TiO}_{2}$ 晶格 $\left(\mathrm{Ti}_{1-x} \mathrm{Sn}_{x} \mathrm{O}_{2}\right)$, 其掺杂能级在导带下 $0.38 \mathrm{eV}$. 当 $\mathrm{Sn}^{4+}$ 离子浓度较高时 $\left(\mathrm{TiO}_{2}-\mathrm{Sn} 50 \%\right), \mathrm{Sn}^{4+}$ 离子在 $\mathrm{TiO}_{2}$ 表面生成金红石 $\mathrm{SnO}_{2}$, 形成 $\mathrm{TiO}_{2}$ 和 $\mathrm{SnO}_{2}$ 复合结构 $\left(\mathrm{TiO}_{2} / \mathrm{SnO}_{2}\right)$, 其 $\mathrm{SnO}_{2}$ 导带位于 $\mathrm{TiO}_{2}$ 导带下 $0.33 \mathrm{eV}$. 与纯 $\mathrm{TiO}_{2}$ 相比, 在 $\mathrm{TiO}_{2}-\mathrm{Sn} 5 \%$ 和 $\mathrm{TiO}_{2}-\mathrm{Sn} 50 \%$ 样品中, $\mathrm{Sn}^{4+}$ 离子掺杂能级或表面 $\mathrm{SnO}_{2}$ 能带的存在, 有效地促进了光生载流子的分离, 阻止其复合, 而 且增加了催化剂的光谱吸收范围. 另外, 与表面 $\mathrm{SnO}_{2}$ 能带相比, $\mathrm{Sn}^{4+}$ 离子的掺杂能级更有利于增加 光生载流子的寿命, 降低了表面光生电子与价带光 生空穴复合的几率, 提高光生载流子的分离效率; 因此, 催化剂的紫外光催化活性呈现出 $\mathrm{TiO}_{2}-\mathrm{Sn} 5 \%$ $\left(\mathrm{Ti}_{1-x} \mathrm{Sn}_{x} \mathrm{O}_{2}\right)>\mathrm{TiO}_{2}-\mathrm{Sn} 50 \%\left(\mathrm{TiO}_{2} / \mathrm{SnO}_{2}\right)>\mathrm{TiO}_{2}$ 的规律.

\section{References}

(1) Fujishima, A.; Honda, K. Nature 1972, 238, 37. doi: 10.1038/ $238037 \mathrm{a} 0$

(2) Grätzel, M. Nature 2001, 414, 338. doi: 10.1038/35104607

(3) Khan, S.; Al-Shahry, M.; Ingler, W. Science 2002, 297, 2243. doi: $10.1126 /$ science. 1075035

(4) Yu, H.; Chen, S.; Quan, X.; Zhao, H.; Zhang, Y. Environ. Sci. Technol. 2008, 42, 3791. doi: 10.1021/es702948e

(5) Asahi, R.; Morikawa, T.; Ohwaki, K.; Aoki, K.; Taga, Y. Science 2001, 293, 269. doi: 10.1126/science.1061051

(6) Francioso, L.; Presicce, D.; Siciliano, P.; Ficarella, A. Sensors and Actuators B 2007, 123, 516. doi: 10.1016/j.snb.2006.09.037

(7) Zhao, W.; Ma, W.; Chen, C.; Zhao, J.; Shuai, Z. J. Am. Chem. Soc. 2004, 126, 4782. doi: 10.1021/ja0396753

(8) Zhang, J.; Wu, Y.; Xing, M.; Leghari, S.; Sajjad, S. Energy Environ. Sci. 2010, 3, 715. doi: 10.1039/b927575d

(9) Ji, P.; Takeuchi, M.; Cuong, T.; Zhang, J.; Matsuoka, M.; Anpo, M. Research on Chemical Intermediates 2010, 36, 327. doi: 10.1007/s11164-010-0142-5

(10) Luo, D. C.; Zhang, L. L.; Long, H. J.; Chen, Y. M.; Cao, Y. A. Acta Phys. -Chim. Sin. 2008, 24, 1095 . [罗大超, 张兰兰, 龙绘 锦, 陈咏梅, 曹亚安. 物理化学学报, 2008, 24, 1095.] doi: 10.3866/PKU.WHXB20080632

(11) Li, K. Y.; Guo, J.; Liu, T.; Zhou, B. J.; Li, Y. Acta Phys. -Chim. 
Sin. 2008, 24, 2096. [李葵英, 郭 静, 刘 通, 周冰晶, 李 悦. 物理化学学报, 2008, 24, 2096.] doi: 10.3866/PKU. WHXB20081127

(12) Zhou, X.; Lu, J.; Li, L.; Wang, Z. Journal of Nanomaterials 2011, 2011, 432947.

(13) Mahanty, S.; Roy, S.; Sen, S. Journal of Crystal Growth 2004, 261, 77. doi: 10.1016/j.jcrysgro.2003.09.023

(14) Gu, Q.; Long, J.; Zhou, Y.; Yuan, R.; Lin, H.; Wang, X. Journal of Catalysis 2012, 289, 88. doi: 10.1016/j.jcat.2012.01.018

(15) Zheng, T.; Tian, Z.; Sun, J. X.; Su, B. T.; Lei, Z. Q. Chemical Research and Application 2012, 24, 1. [郑 奉, 田 泽, 孙佳 星, 苏碧桃, 雷自强. 化学研究与应用, 2012, 24, 1.]

(16) Duan, Y.; Fu, N.; Liu, Q.; Fang, Y.; Zhou, X.; Zhang, J.; Lin, Y. J. Phys. Chem. C 2012, 116, 8888. doi: 10.1021/jp212517k

(17) Cao, Y.; He, T.; Zhao, L.; Wang, E.; Yang, W.; Cao, Y. J. Phys. Chem. C 2009, 113, 18121. doi: 10.1021/jp9069288
(18) Cao, Y.; Yang, Y.; Zhang, W.; Liu, G.; Yue, P. New J. Chem. 2004, 28, 218. doi: 10.1039/b306845e

(19) Wang, Y.; Ma, C.; Sun, X.; Li, H. Nanotechnology 2002, 13, 565. doi: 10.1088/0957-4484/13/5/304

(20) Li, J.; Zeng, H. J. Am. Chem. Soc. 2007, 129, 15839. doi: $10.1021 / \mathrm{ja} 073521 \mathrm{w}$

(21) Xu, H.; Zhang, L. J. Phys. Chem. C 2010, 114, 11534. doi: $10.1021 /$ jp1027965

(22) Bullock, E.; Patthey, L.; Steinemann, S. Surface Science 1996, 352, 504. doi: 10.1016/0039-6028(95)01188-9

(23) Li, D.; Haneda, H.; Hishita, D.; Ohashi, N. Chem. Mater. 2005, 17, 2596. doi: 10.1021/cm049099p

(24) Serpone, N.; Lawless, D.; Khairutdinov, R. J. Phys. Chem. 1995, 99, 16646. doi: 10.1021/j100045a026

(25) Yuan, J.; Wu, Q.; Zhang, P.; Yao, J.; He, T.; Cao, Y. Environ. Sci. Technol. 2012, 46, 2330. doi: 10.1021/es203333k

\section{第十三届全国均相催化学术讨论会第一轮通知}

\section{一、会议介绍}

由中国化学会催化委员会均相催化专业委员会主办, 中国科学院兰州化学物理研究所和苏州大学材料与化学化工学部 联合承办的第十三届全国均相催化学术讨论会定于 2013 年9月25-27日在美丽的苏州举行。本届会议是全国均相催化和相 关领域专家学者的一次聚会, 将全面展示两年来我国在这些领域取得的研究成果, 交流和讨论均相催化发展的新趋势和所面 临的机遇与挑战, 以推动我国均相催化领域的研究和相关产业向更高的目标迈进。

\section{二、会议主办单位: 均相催化专业委员会}

主任:夏春谷

副主任:丁奎岭、李贤均

秘书长: 孙伟

委员: 包明、陈静、范青华、龚流柱、郭灿城、贺德华、胡信全、华瑞茂、江焕峰、金国新、雷爱文、李光兴、梁永民、陆维敏、施章杰、 王公应、王向宇、吴鹏、吴静、徐杰、夏清华、游书力、袁友珠、周永贵

\section{三、征文范围}

1. 均相催化剂的设计、合成和表征; 2. 均相酸碱催化反应; 3. 不对称催化反应; 4. 小分子催化; 5. 生物催化与仿生催化反应; 6 . 胶束和胶体催化, 以及微乳催化反应; 7. 纳米催化剂的制备、表征和催化反应; 8. 光、电催化反应; 9. 生物质催化转化; 10. 均相 催化剂的多相化; 11. 均相催化的工业应用; 12. 与均相催化相关的反应机理、理论和计算化学等

\section{四、投稿要求及日期}

详细论文摘要的格式要求, 请登录会议网站: http://13nchc.csp.escience.cn/det/pag。论文经评审录用后, 发出录用通知。被 录用的论文一般不再退回修改, 作者在寄论文摘要时应做好一次性定稿准备, 文责自负。论文录用与否, 一概不退, 请作者自留 底稿。征文截止日期为 2013 年6月30日,请登陆会议网站进行在线投稿或通过Email (13nchc@licp.cas.cn)发送征文电子版。

\section{五、会议承办单位及联系人}

1. 中国科学院兰州化学物理研究所 羰基合成与选择氧化国家重点实验室

地址: 甘肃省兰州市天水中路 18 号; 邮编: 730000

联系人: 李福伟、牛建中

联系电话: +86-931-4968528; 4968126; 传真: +86-931-4968129;

E-mail: fuweili@licp.cas.cn; njz@licp.cas.cn

2. 苏州大学材料与化学化工学部

地址: 江苏省苏州市工业园区仁爱路 199 号 907 栋; 邮编: 215123

联系人:王兴旺

联系电话:+86-512-65880378; Email: wangxw@suda.edu.cn 